\title{
PHARMACOGNOSTICAL SCREENING AND DETERMINATION OF ANTIOXIDANT ACTIVITY OF NELUMBO NUCIFERA GAERTN ETHANOL SEED EXTRACT BY DIFFERENT IN VITRO MODELS
}

\author{
ALOK BHARDWAJ ${ }^{1}$, KETAN. P. MODI ${ }^{2}$ \\ 1School of Pharmacy, RK University, Rajkot, Gujarat, India, Ram-Eesh Institute of Vocational and Technical Education, Greater Noida, \\ 2B. K. Mody Govt. Pharmacy College, Rajkot, Gujarat, India \\ Email: alok.nicholas@gmail.com \\ Received: 27 Nov 2016 Revised and Accepted: 09 Jan 2017
}

\begin{abstract}
Objective: To perform the pharmacognostical screening and determination of antioxidant activity of Nelumbo nucifera Gaertn ethanol seed extract by different in vitro models.

Methods: The different pharmacognostical parameters were evaluated as per standard protocols with some modifications. The various concentrations of ethanol seed extract of Nelumbo nucifera were evaluated for antioxidant activity using the standard in vitro methods like hydrogen peroxide $\left(\mathrm{H}_{2} \mathrm{O}_{2}\right)$ scavenging assay, nitric oxide (NO) radical scavenging assay, reducing power capacity assessment, $\beta$-Carotene bleaching assay, ferric thiocyanate method (FTC) and thiobarbituric acid (TBA) assay.

Results: Extractive values, ash values and moisture content values of Nelumbo nucifera were found to be as per the IP 2007 and Ayurvedic pharmacopoeia standard. Among the four extracts viz. Petroleum ether, chloroform, ethanol and aqueous, the ethanol extract showed significant antioxidant activity. The ethanol seed extract of Nelumbo nucifera (NNSE) exhibited high antioxidant activity (IC ${ }_{50}=12.65 \mu \mathrm{g} / \mathrm{ml}$ ) in 1,1 -diphenyl-2picryldydrazyl (DPPH) radical scavenging assay. In FTC method the absorbance of NNSE increased slowly, which shows strong antioxidant ability. The thin layer chromatography (TLC) of the extract revealed 6 spots with the Rf values $0.41,0.47,0.59,0.65,0.67,0.74$ with the solvent system of toluene: ethyl acetate: formic acid (5:4:0.5, v/v/v). The high-performance thin layer chromatography (HPTLC) revealed the spots at Rf values 0.65 and 0.68 . These fractions obtained by preparative TLC also confirmed the same.
\end{abstract}

Conclusion: The present investigation suggested that the NNSE has significant antioxidant activity. These results clearly indicate that Nelumbo nucifera is effective against free radical mediated diseases, thus replacing the synthetic ones.

Keywords: Nelumbo nucifera, Antioxidant, Pharmacognostical, Seed extract

(C) 2016 The Authors. Published by Innovare Academic Sciences Pvt Ltd. This is an open access article under the CC BY license (http://creativecommons.org/licenses/by/4. 0/) DOI: http://dx.doi.org/10.22159/ijpps.2017v9i3.16362

\section{INTRODUCTION}

Oxidative stress explains the relation between the free radicals and diseases [1]. The major free radicals, reactive oxygen species (ROS) have a dual effect on the metabolism. An imbalance of these radical species results in the damage of proteins, lipids, nucleic acids, and cell structures [2]. This is associated with the pathogenesis of various diseases like fibrosis, rheumatoid arthritis, atherosclerosis, cardiovascular diseases, hypertension and diabetes mellitus $[3,4]$.

On the other hand, ROS are very harmful for body cells. They may damage phospholipids bilayer cell membranes and DNA of the nucleus. They also contribute to cell membrane disintegration, protein damage and DNA mutation, which can lead to the development of diseases as diabetes, cancer, inflammation [4]. Antioxidants are one among the various defence mechanisms against oxidative stress [5].

Herbal medicines are the choice of drugs which represented the most potential field of alternative medicines. Indian population mainly depends on the traditional system of medicine to maintain their physical and psychological health. Herbal medicines have given encouraging results and can be used as an important adjuvant therapy [6].

It is very essential to study the medicinal plants so that we can promote their judicious use and their potential to cure different types of diseases. Indian system of medicine includes Unani, Siddha and Naturopathy which is mainly based on the medicinal plants developed over a period of time. The modern allopathic system uses synthetic drugs which have side effects and adverse effects due to these reason herbal medicines are getting more importance in the treatment of different diseases [7].
Now-a-days there is an increase in the demand of natural drugs as they are considered green medicines which are always supposed to be safe. The main advantage of using natural drugs is their easy availability, economic rate and less side effects, but the disadvantage is that they are the victims of adulteration. The chances of adulteration are more in the case of a natural drug which are more effective because it's more in demand. So the natural drugs are easily adulterated with low-grade material to meet the demand. Adulteration is the mixing of some cheap material or substitution of the original plant with other plant material to increase the weight or the potency of the plant. The phytochemical screening ensures safety and efficacy of natural medicinal plants, therefore the present study was carried out to assess antioxidant activity of Nelumbo nucifera Gaertn ethanol seed extract [8].

Nelumbo nucifera Gaertn is widely distributed plant in Southeast Asia. It has many synonyms like Indian lotus, sacred lotus etc. The plant Nelumbo nucifera Gaertn is the currently recognized name for this species, which has been classified previously as Nelumbium speciosum (Wild) and Nymphaea nelumbo. Lotus is considered sacred in many religions as a symbol of purity, divine beauty and enlightenment. It is one of the most important medicinal plants in India [6].

The therapeutic efficacy of medicinal plants only depends upon its purity, quality and amount of active phytoconstituents presents. The chances of misuse of medicinal plants start with wrong identification because one vernacular name is given to different species of the plant. So to avoid these problems, standardization of medicinal plants is very essential. A pharmacognostic standardization of medicinal plants ensures identity and other important parameters which minimizes adulterations. Such types of studies also help on authentication of the plants and ensure reproducible quality of 
herbal products. Therefore, the present study aims to investigate the antioxidant activities of Nelumbo nucifera Gaertn along with the determination of total flavonoids content [TFC] [8].

\section{MATERIALS AND METHODS}

\section{Plant material}

Seeds of the plant were collected and purchased from the bank of Yamuna river near New Delhi. The plant was identified and authenticated by the Dr Anjula Pandey principal scientist, NBPGR, Pusa Institute, New Delhi (identification voucher no.: NHCP/ NBPGR/2014-10). The plant seeds were dried in air for complete drying.

\section{Preparation of extracts}

The seeds were dried and seed powder was made by a domestic grinder. The powdered drug of the plant has been subjected to successive solvent extraction, with petroleum ether, chloroform, ethanol and water. After complete extraction, the solvent was evaporated at room temperature under pressure. The percentage yield, colour other characteristic of the semisolid was determined. The extract was preserved in a desiccator at 4 ${ }^{\circ} \mathrm{C}$ till further use.

\section{Chemicals, reagents and solvents}

Griess reagent, ammonium thiocyanate, 1,1-diphenyl-2-picrylhydrazyl (DPPH), thiobarbituric acid and 3-(2-Pyridyl)-5,6-bi's (4phenyl-sulfonic acid)-1,2,4-triazine (frozen) were purchased from Sigma chemical Co. Ltd, USA. Butylated hydroxytoluene (BHT), hydroxylamine, ferrous chloride, ascorbic acid (vitamin $\mathrm{C}$ ), nitro blue tetrazolium, EDTA, $\beta$-carotene, tween-80, trichloracetic acid (TCA) and eosin were purchased from Himedia Mumbai and Central Drug House (CDH) New Delhi. All others unlabelled chemicals and reagents were of analytical grade.

The pharmacognostic standardization parameters of Nelumbo nucifera Gaertn were performed. The various standardisation parameters of the plant were evaluated as per WHO guidelines like a loss on drying, ash vale, extractive values, and phytochemical investigations, thin layer chromatography and high-performance thin layer chromatography.

\section{Phytochemical investigations}

Phytochemical tests of the different extracts were conducted with various qualitative tests to identify the presence of alkaloids, flavonoids, saponins and steroids using a standard test like Mayer's test, Molisch's test, Modified borntrager's test, Libermann Burchard's test.

\section{Estimation of total flavonoids content}

The method given by Kim et al. was used to determine the total flavonoid content. To determine the total flavonoids content $1 \mathrm{ml}$ extract of $1000 \mu \mathrm{g} / \mathrm{ml}$ concentration was taken and $4 \mathrm{ml}$ of distilled water was added and then $0.3 \mathrm{ml} \mathrm{NaNO}{ }_{2}$ and $0.3 \mathrm{ml} \mathrm{AlCl}_{3}$ was added. The final solution was incubated for $10 \mathrm{~min}$ at room temperature. 2 $\mathrm{ml}$ of $\mathrm{NaOH}$ and $2.4 \mathrm{ml}$ distilled water was added to the incubated solution and the absorbance was measured at $510 \mathrm{~nm}$. The total flavonoids content of NNSE was estimated from the standard curve. Total flavonoids content was expressed as routing/quercetin equivalents in $\mathrm{mg} / \mathrm{g}$ of the dry sample [9].

\section{Thin layer chromatography}

TLC profile is an important analytical tool in the separation and identification of different classes of natural products. TLC of seed extract was done by using standard procedures and was mainly used for the detection of the nature of phyto-constituents present.

\section{Development of the optimum mobile phase by TLC}

- Different solvent systems with different ratio were tried.

- The solvent system which showed the best separation of the components was selected for the extract.
- The thin layer chromatography procedure was adopted to evaluate the ethanol extract. Initially toluene: ethyl acetate: formic acid in different ratios was tried. The combination of toluene: ethyl acetate: formic acid $(5: 4: 0.5, \mathrm{v} / \mathrm{v} / \mathrm{v})$ as mobile phase gave a satisfactory resolution.

- Sharp and well-defined spots were obtained with a mobile phase consisting of $(5: 4: 0.2, v / v / v)$ when the chamber was saturated with mobile phase for $20 \mathrm{~min}$ at room temperature.

- The thin layer chromatography plate was visualized under UV light.

\section{HPTLC procedure for estimation of quercetin in NNSE}

On the basis of phytochemical screening of different seed extracts of Nelumbo nucifera Gaertn, the ethanol seed extract was found to be more active among petroleum ether and chloroform. Thin layer chromatography studies were performed using various solvent systems with a different ratio. The solvent system which showed the best separation of the components was selected. The solvents were purified prior to chromatographic analysis for a better separation of phytoconstituents.

\section{- Stationary phase: silica gel 60 GF 254 .}

- The mobile phase toluene: ethyl acetate: formic acid (5:4:0.2, $\mathrm{v} / \mathrm{v} / \mathrm{v})$

- An instrument used: Win cat's planar chromatography manager.

\section{- Applicator: linomat IV, software: raincoats}

The ethanol seed extract of Nelumbo nucifera was chromatographed on silica gel 60 plates with a combination of toluene: ethyl acetate: formic acid (5:4:0.5, v/v/v) as the mobile phase. The peak purity of quercetin was assessed by comparing the spectra at peak start, peak apex and peak end positions on the spot [9].

\section{In vitro methods to assess antioxidant activity}

Antioxidant activity should not be concluded based on one or two antioxidant test model. Therefore, several in vitro test procedures were carried out to establish the antioxidant activity of the plant [10].

\section{Hydrogen peroxide $\left(\mathrm{H}_{2} \mathrm{O}_{2}\right)$ scavenging assay}

Scavenging activity of extracts and its sub-fractions were evaluated by hydrogen peroxide. $1 \mathrm{ml}$ of various concentrations of the extract, sub-fractions and standards in ethanol were added to $2 \mathrm{ml}$ of hydrogen peroxide solution in phosphate buffered saline ( $\mathrm{pH}$ 7.4). Then finally the absorbance was measured at $230 \mathrm{~nm}$ after $10 \mathrm{~min}$. Ascorbic acid and butylated hydroxytoluene were used as a standard. A control sample was prepared containing the same volume without any extract and standard. The absorbance was read at $230 \mathrm{~nm}$ using a spectrophotometer. The percentage inhibition was calculated by using the following formula:

$$
\% \text { inhibition }=\left(1-\frac{\mathrm{A} 1}{\mathrm{~A} 0}\right) \times 100
$$

Where, $\mathrm{A} 0=$ observance of the control and $\mathrm{A} 1=$ absorbance in the presence of the sample of extract and standard [11].

\section{Nitric oxide (NO) radical scavenging assay}

The radical scavenging assay was performed by the method described by the Sreejayan method. The assay was carried out using Griess reagent $2 \mathrm{ml}$ of $10 \mathrm{mmol}$ sodium nitro-prusside in $0.5 \mathrm{ml}$ phosphate buffer ( $\mathrm{pH} 7.4$ ) was mixed with $0.5 \mathrm{ml}$ of extract at different concentrations. The resultant mixture was incubated at 25 ${ }^{\circ} \mathrm{C}$ for $150 \mathrm{~min} .0 .5 \mathrm{ml}$ out of incubated mixture was added with 1.0 $\mathrm{ml}$ sulphanilic acid reagent and further incubated at room temperature for $5 \mathrm{~min}$. Again $1.0 \mathrm{ml}$ naphthyl ethylenediamine dihydrochloride $(0.1 \% \mathrm{w} / \mathrm{v})$ was mixed and maintained at room temperature for $30 \mathrm{~min}$. The absorbance was measured at $546 \mathrm{~nm}$. The percentage inhibition was calculated by using the following formula: 


$$
\% \text { inhibition }=\left(1-\frac{A 1}{A 0}\right) \times 100
$$

Where, $\mathrm{A} 1=$ Absorbance of the extract or standard and $\mathrm{A} 0=$ Absorbance of the control [12].

\section{Reducing power capacity assessment}

Assay of reducing power was carried out by using Yildirim method. $1 \mathrm{ml}$ of extract and its sub-fractions (concentration $25-100 \mu \mathrm{g} / \mathrm{ml}$ ) were mixed with $2.5 \mathrm{ml}$ phosphate buffer (0.2 M, pH 6.6) and $2.5 \mathrm{ml}$ $\mathrm{K}_{3} \mathrm{Fe}(\mathrm{CN}){ }_{6}$. The final mixture was incubated at $50{ }^{\circ} \mathrm{C}$ for $20 \mathrm{~min}$. After incubation $2.5 \mathrm{ml}$ of trichloroacetic acid was added, centrifuged at $3000 \mathrm{rpm}$ for $30 \mathrm{~min}$. Finally, $2.5 \mathrm{ml}$ of the upper layer of the solution, i.e. the supernatant solution was collected and mixed with $2.5 \mathrm{ml}$ of distilled water and $0.5 \mathrm{ml}$ ferric chloride. The absorbance was measured at $700 \mathrm{~nm}$. Ascorbic acid and BHT were used as standard and phosphate buffer as a blank solution. The increased absorbance indicates increased, reducing power [13].

\section{$\beta$-Carotene bleaching assay}

The $\beta$-Carotene bleaching assay was determined using a Dapkevicius et al. method by measuring the inhibition of hydro peroxides formed from linoleic acid oxidation. The Linoleic acid solution was prepared by mixing $0.5 \mathrm{mg} \beta$-carotene in $1 \mathrm{ml} \mathrm{CHCl}_{3}$, then $25 \mu$ linoleic acid and $200 \mathrm{mg}$ tween $40 . \mathrm{CHCl}_{3}$ was totally evaporated using vacuum evaporator and $100 \mathrm{ml}$ of distilled water was added, followed by shaking. Finally $3 \mathrm{ml}$ of the above solution was transferred to the test tube and $0.2 \mathrm{ml}(500 \mu \mathrm{l})$ of each extract was added. Same procedure as above was followed for blanks ( $\beta$-carotene stock solution in addition to the solvents). All samples were put into a water bath for $2 \mathrm{~h}$ at $50{ }^{\circ} \mathrm{C}$. The absorbance value was measured at $470 \mathrm{~nm}$. Measurement of observance was continued until the colour of $\beta$-carotene disappeared; every $30 \mathrm{~min}$ up to 2 the percentage inhibition was calculated by using the following formula: [14].

$$
\% \text { Inhibition }=\frac{\text { Control absorbance }- \text { sample absorbance }}{\text { control absorbance }} \times 100
$$

\section{Antioxidant activity by FTC and TBA method}

The FTC method was adopted from Osawa and Namiki. $1 \mathrm{ml}$ of seed extract was mixed with $1 \mathrm{ml} 2.5 \%$ linoleic acid, $2 \mathrm{ml}$ phosphate buffer ( $50 \mathrm{mmol}$ ), and $1 \mathrm{ml}$ distilled water. $0.1 \mathrm{ml}$ portions were mixed with $9.7 \mathrm{ml}$ ethanol and $0.1 \mathrm{ml} \mathrm{NH}_{4} \mathrm{SCN}$. Ferrous chloride 0.1 $\mathrm{ml}$ (20 mmol) was added to each sample and absorbance was measured at $500 \mathrm{~nm}$. A small portion was taken and assayed in an identical fashion at $24 \mathrm{~h}$ intervals until a constant value achieved. Control without sample and standard containing vitamin $\mathrm{C}$ and $\mathrm{BHT}$ $(100 \mu \mathrm{g} / \mathrm{ml})$ in place of the seed extract sample were subjected to the same procedure [15].

The TBA assay was adopted from Kikuzaki and Nakatani method. According to the method $1 \mathrm{ml}$ TBA and $1 \mathrm{ml}$ trichloracetic acid added to $0.5 \mathrm{ml}$ of reaction solution that was prepared same as FTC method. The mixture was placed in a boiling water bath for $15 \mathrm{~min}$ and centrifuged for $20 \mathrm{~min}$. The absorbance of the supernatant was determined at $532 \mathrm{~nm}$. The lower absorbance value indicates strong antioxidant activity. The inhibition rate was calculated by the following formula: [16].

$$
\begin{aligned}
& \text { Inhibition rate } \\
& =\frac{\text { Absorbance of control }- \text { absorbance of sample }}{\text { Absorbance of control }} \times 100
\end{aligned}
$$

(Ac = absorbance of control; As = absorbance of sample $)$

\section{Statistical analysis}

All the experiments were performed in triplicate, and the data were expressed as mean \pm SEM.

\section{RESULTS}

\section{Physico-chemical analysis}

The percentage yield, colour and other characteristic of the semisolid was determined. The percentage yield of different extracts was measured and found to be maximum for ethanol extract $(14.26$ $\%)$ and minimum for chloroform extract (10.52\%).

Some of the important physicochemical analysis was carried out like a loss on drying, total ash, acid-insoluble ash and different extractive values. These values are important for the evaluation of crude drugs because extracting values give an idea about the nature of phyto-

\begin{tabular}{|c|c|c|}
\hline Nelumbo nucifera gaertn (Sample) & Extracting value $(\% w / w) \pm S E M$ & IP 2007 and Ayurvedic Pharmacopoeia \\
\hline Alcohol soluble extracts & $8.25 \pm 0.206$ & Alcohol-soluble extractive $\leq 6 \%$ \\
\hline Water soluble extractives & $15.29 \pm 0.546$ & Water-soluble extractive $\leq 14$ per cent \\
\hline \multirow[t]{5}{*}{ Chloroform soluble extracts } & $10.42 \pm 0.239$ & 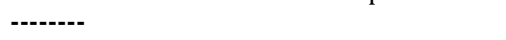 \\
\hline & 0.239826 & \\
\hline & 0.239826 & \\
\hline & 0.239826 & \\
\hline & 0.239826 & \\
\hline Petroleum ether soluble Extractives & $3.86 \pm 0.192$ & ------- \\
\hline Ash value & $3.70 \pm 0.256$ & Total ash not more than $12 \%$ \\
\hline Acid insoluble ash value & $1.01 \pm 0.017$ & Acid-insoluble ash not more than $3 \%$ \\
\hline Water soluble ash value & $1.25 \pm 0.513$ & ------- \\
\hline Moisture content (loss on drying) & $8.25 \pm 0.526$ & Not more than $15 \%$ \\
\hline
\end{tabular}
constituents present in the plant. The various standardization parameters of the plant were evaluated as per WHO guidelines (table 1).

Table 1: Extractive values and ash values of Nelumbo nucifera Gaertn

Values are mean of three independent replicates \pm SEM

\section{Phytochemical analysis}

Petroleum ether, chloroform, ethanol and aqueous extracts were reduced under pressure using rotatory evaporator and phytochemical screening of different extracts of Nelumbo nucifera Gaertn were carried out by using different chemicals and reagents. Phytochemical screening of different seed extracts of Nelumbo nucifera Gaertn confirms the presence of carbohydrates, proteins, glycosides, flavonoids, alkaloids and phenolic compounds [17].

\section{Quantitative determination of total flavonoids}

The quantitative determination of total flavonoids was expressed as quercetin/rutin equivalents which indicated the amount of flavonoids equal to quercetin or rutin in one gram of dry material. The total flavonoids content was found to be $(17.90 \pm 0.62 \mathrm{QE}$ and $25.77 \pm 0.88 \mathrm{RE} \mathrm{mg} / \mathrm{g}$ of dry material) in NNSE.

\section{TLC and HPTLC findings}

A photograph of a thin layer chromatography plate of ethanol extract of dried seeds of Nelumbo nucifera is shown in fig. 1. The identity of the quercetin bands in sample chromatograms was confirmed by the chromatogram obtained from the reference standard solution (fig. 1) and by comparing retention factors of the sample and standard solutions. The peak corresponding to quercetin from the sample solution ( $\mathrm{Rf} 0.65$ ) had same retention factor as that of the quercetin standard (Rf 0.68) (fig. 2). The TLC and HPTLC 
findings provide a good resolution of quercetin from other constituents present in the ethanol seed extract of Nelumbo nucifera.

Determination of antioxidant activity by using different in vitro models

Hydrogen peroxide scavenging $\left(\mathrm{H}_{2} \mathrm{O}_{2}\right)$ assay

The NNSE exhibited high antioxidant activity $\left(\mathrm{IC}_{50}=12.65 \mu \mathrm{g} / \mathrm{ml}\right.$ ) in the DPPH radical scavenging assay. The hydrogen peroxide $\left(\mathrm{H}_{2} \mathrm{O}_{2}\right)$ scavenging assay of NNSE was compared with the standards like butylated hydroxytoluene and vitamin $C$. The percentage of scavenging hydrogen peroxide determined at $15 \mu \mathrm{g} / \mathrm{ml}$ concentration was found to be as NNSE (57.00\%), vitamin C (48.02\%), and BHT $(50.64 \%)$ respectively. The order of their antioxidant activity was found to be as NNSE $>$ BHT > vitamin C (fig. 3).
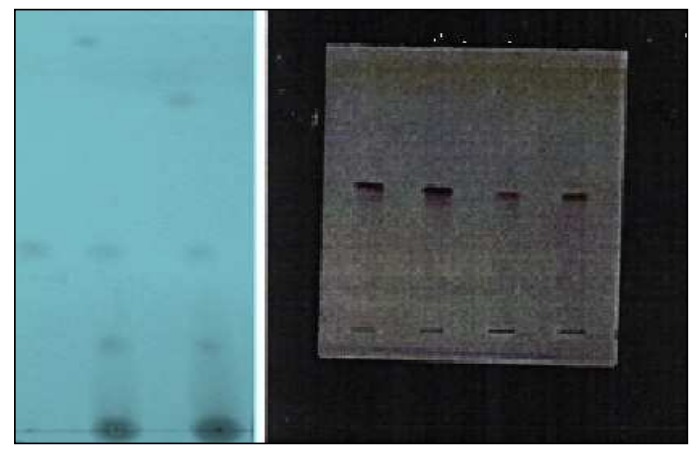

Fig. 1: TLC and HPTLC of Nelumbo nucifera seed extract

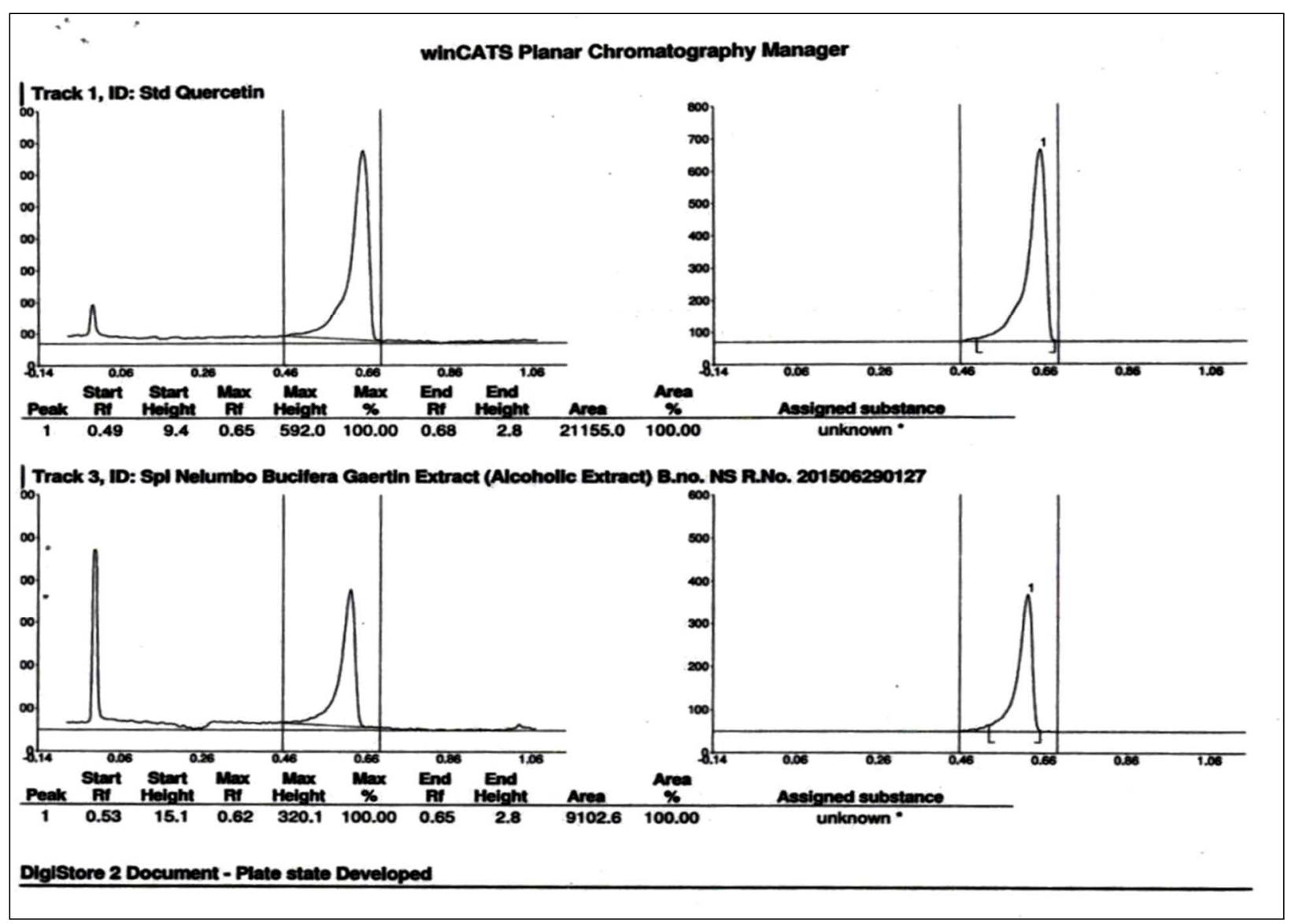

Fig. 2: HPTLC for estimation of quercetin in NNSE

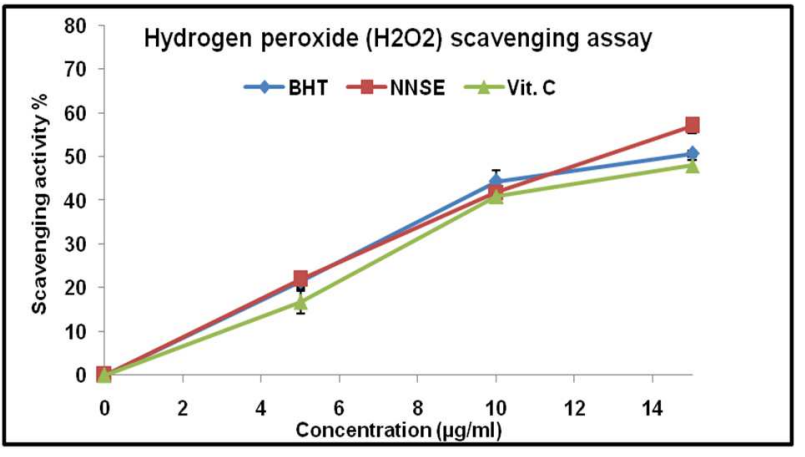

Fig. 3: Hydrogen peroxide scavenging assay of NNSE. Results are mean \pm SEM $(n=3)$ of three parallel determinations; NNSE-

Nelumbo nucifera seed extract; vitamin C-ascorbic acid; BHTbutylated hydroxytoluene

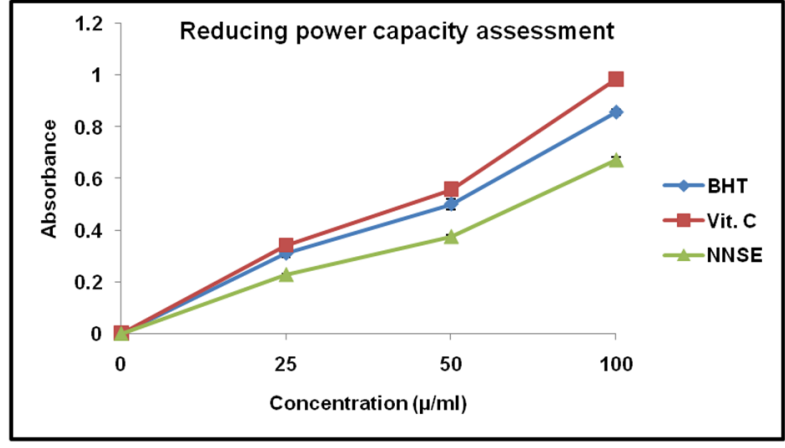

Fig. 4: Reducing power capacity assessment of NNSE compared with that of BHT and vitamin $C$. Results are mean \pm SEM $(n=3)$ of

three parallel determinations; NNSE-Nelumbo nucifera seed extract; vitamin C-ascorbic acid; BHT-butylated hydroxytoluene 


\section{Reducing power capacity assessment}

In this assay, the curve of NNSE at different concentrations $(25,50$, $100, \mu / \mathrm{ml}$ ) was compared with that of vitamin $\mathrm{C}$ and BHT. The antioxidant activity was found directly proportional to the increase in absorbance of the reaction mixture. The reducing power determined at $50 \mu \mathrm{g} / \mathrm{ml}$ was found to be as NNSE $(0.376 \pm 0.005)$, vitamin $C(0.558 \pm 0.009)$ and BHT $(0.502 \pm 0.021)$ respectively. The reducing power of the extract increased with increase in sample concentration and finally the order of reductive potential was found to be as vitamin $\mathrm{C}>\mathrm{BHT}>\mathrm{NNSE}$ (fig. 4).

\section{Nitric oxide (NO) radical scavenging assay}

The ethanol extract of Nelumbo nucifera has potent NO scavenging activity. The percentage of scavenging NO at $200 \mu \mathrm{g} / \mathrm{ml}$ of NNSE, BHT and vitamin C was found to be $64.84 \%, 37.84 \%$, and $32.60 \%$ respectively. The NO scavenging effect of the NNSE, BHT and vitamin $\mathrm{C}$ was found to be as NNSE $>$ BHT $>$ vitamin $\mathrm{C}$ (fig. 5).

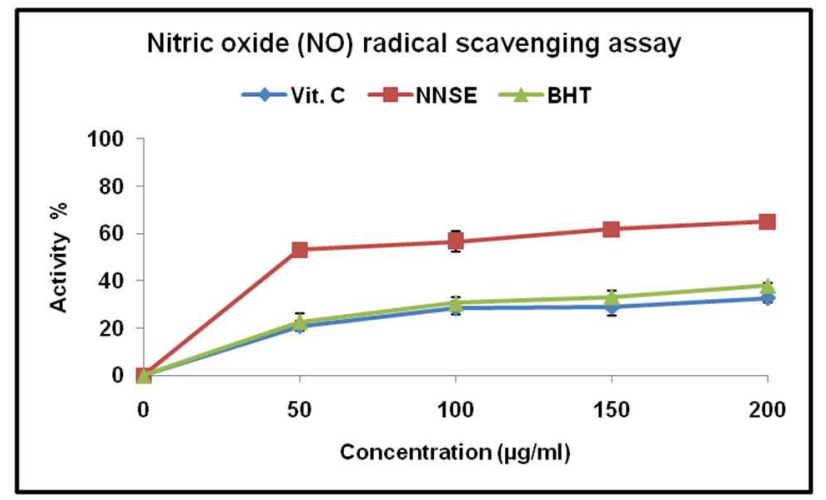

Fig. 5: Comparative nitric oxide (NO) radical scavenging assay of NNSE ascorbic acid and BHT. Results are mean \pm SEM $(n=3)$ of three parallel determinations; NNSE-Nelumbo nucifera seed extract; vitamin C-ascorbic acid; BHT-butylated hydroxytoluene

\section{$\beta$-Carotene bleaching assay}

The absorbance of the control and vitamin $\mathrm{C}$ was observed. It was found that absorbance of control and vitamin $C$ decreased rapidly as compared to NNSE. By this, we can conclude that NNSE is as effective as butylated hydroxyl toluene and much more effective than vitamin $C$. The NNSE was found to be a good antioxidant (fig. 6).

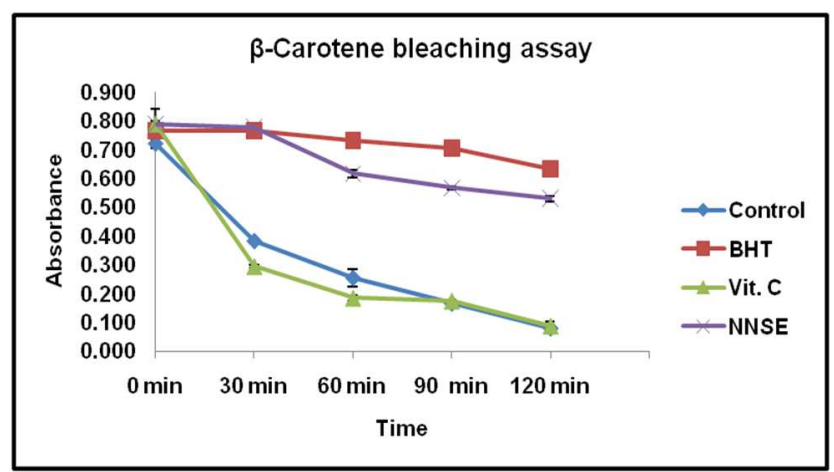

Fig. 6: Antioxidant activity of NNSE in the beta-carotene bleaching assay system. High absorbance indicates strong antioxidant activity; NNSE-Nelumbo nucifera seed extract; vitamin C-ascorbic acid; BHT-butylated hydroxytoluene

\section{Antioxidant activity in a linoleic acid system using FTC method}

Butylated hydroxytoluene showed almost constant absorbance with high capacity to inhibit peroxidation of linoleic acid. The absorbance of NNSE increased slowly, which shows strong antioxidant ability. The absorbance of the NNSE was higher than BHT but lower than vitamin $C$. Therefore NNSE had a stronger antioxidant activity than vitamin $\mathrm{C}$ but less than BHT (fig. 7).

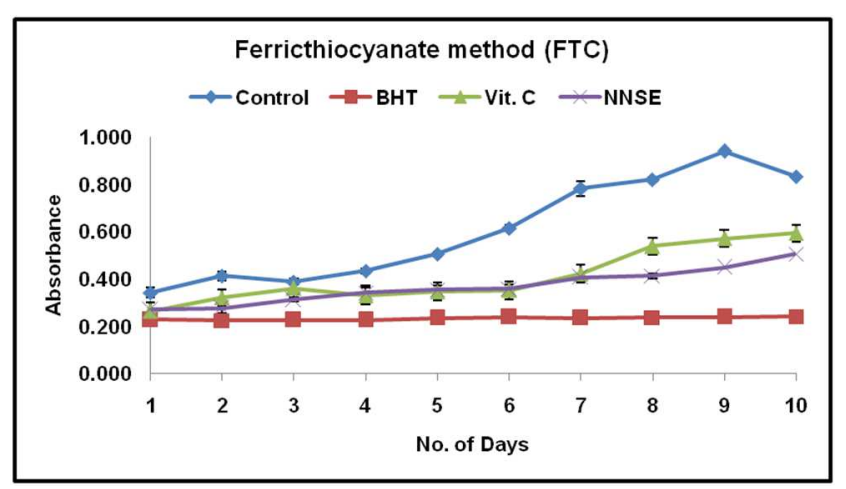

Fig. 7: Antioxidant activity of NNSE by FTC method. Low absorbance indicates high antioxidant activity; NNSE-Nelumbo nucifera seed extract; vitamin C-ascorbic acid; BHT-butylated hydroxytoluene

\section{Thiobarbituric acid assay}

The absorbance values obtained for NNSE, BHT and vitamin C were $1.30 \pm 0.145,1.11 \pm 0.135$, and $1.59 \pm 0.098$ respectively, which were compared with control values of $1.54 \pm 0.062$. It was concluded that the antioxidant activity of NNSE was more than vitamin $\mathrm{C}$ but less than BHT. (fig. 8).

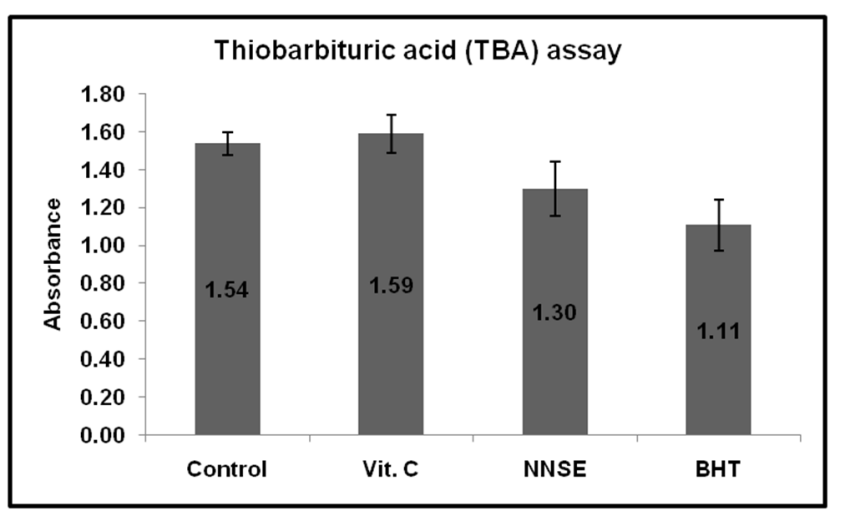

Fig. 8: Antioxidant activities of NNSE by TBA assay. Low absorbance indicates strong antioxidant activity; NNSENelumbo nucifera seed extract; vitamin C-ascorbic acid; BHTbutylated hydroxytoluene

\section{DISCUSSION}

Natural products are one of the rich sources of the new chemical entity and an integral part of today's pharmaceutical industry. Most of the world's population mainly depends on herbal medicine for primary health care because of better compatibility with the human body, easy availability and less side effects. There are some diseases for which allopathic medicines have no solutions in those conditions; herbal medicines are the choice of drugs which represented the most potential field of alternative medicine. Indian population mainly depends on the traditional system of medicine to maintain their physical and psychological health. Herbal medicines have given encouraging results and can be used as an important adjuvant therapy. Considering these facts, in the present study, pharmacognostical analysis and in vitro antioxidant activity of NNSE was carried out. In pharmacognostical screening extractive 
values, moisture content and ash values passed the Ayurvedic pharmacopoeia standard. The results obtained from TLC and HPTLC were helpful in the identification and quality control of the drug.

It is now well-established the fact that reactive oxygen species are indirectly involved in the pathophysiology of many diseases such as diabetes, cancer, inflammation, rheumatoid arthritis and atherosclerosis. It is identified by many scientists that antioxidants can inhibit harmful effects of free radicals in our body [18].

In modern days there is an increase trend of using synthetic antioxidants like BHT and tert-butyl hydroquinone (TBHQ) in the food industry. Unfortunately, in the large amount, they are harmful to liver and impose carcinogenic effect in our body [19]. Therefore, there is an urgent need for the development of more effective antioxidants of natural origins [20]. Plants may be an attractive alternative to currently available synthetic antioxidants [21].

$\mathrm{H}_{2} \mathrm{O}_{2}$ probably reacts with $\mathrm{Fe}^{2+}$ and $\mathrm{Cu}^{2+}$ ions to form hydroxyl radical which causes toxic effects on different body cells [22-23]. So the accumulation of hydrogen peroxide in cells is very harmful. Hydrogen peroxide is highly important ROS, which is generated in vivo by several oxidase enzymes, because of its ability to prevent the biological membrane. There is increasing evidence that it may be toxic if converted to hydroxyl radical $(\mathrm{OH} \cdot)$ which cause severe damage to the biological system [24]. So the removal of hydrogen peroxide is very essential for any antioxidant defence in the cell [25]. In the present study, the antioxidant activity of NNSE was much better than BHT and vitamin C.

The presence of reductants in NNSE causes the reduction of the ferric ion into ferrous form which can be measured as blue colour compound at $700 \mathrm{~nm}$. Fe3+is often used as an indicator of electron donating activity and which is an important mechanism of antioxidant action and can be strongly correlated with the other antioxidant properties [26]. The reducing properties of the plant extract are generally associated with the presence of reductones, which have been shown to exert antioxidant action by breaking the free radical chain [27]. The reductones are reported to react with certain precursors of peroxides, thus prevention of peroxide formation [28]. In this present study, NNSE showed significant antioxidant activity in reducing power assay. The reducing power capacity assessment of the seed extract was directly proportional to sample concentration and order of reductive potential was vitamin C>BHT $>$ NNSE.

NO is a chemical substance which plays a variety of biological processes like neuronal messenger, vasodilator, an antimicrobial agent, etc. [29]. It has been reported to react with oxygen radical to form peroxynitrite radicals (ONOO-) which is very toxic for proteins, lipids and nucleic acids. During the event of cell injury and inflammation, cells of the immune system generate superoxide radicals in which NADPH oxidase enzyme plays a crucial role in vascular complications [30]. Nitrate and nitrite produced by NO can be estimated by using Griess reagent. In the presence of a scavenging test compound, the amount of nitrous acid decreases, which can be measured at $546 \mathrm{~nm}$. The degree of decrease information of purple azodye will reflect the extent of scavenging. The absorbance of chromophore formed is measured at $546 \mathrm{~nm}$. In this study, results show that the NNSE produced good nitric oxide scavenging activity and found to be equally potent when compared to the standard [31].

The linoleic acid-free radical attacks $\beta$-Carotene bleaching assay and hence it loses chromophore and orange colour. The antioxidant compounds in Nelumbo nucifera can decrease the extent of discolouration measured at $470 \mathrm{~nm}$. The $\beta$-carotene principle is based on the loss of the orange colour of $\beta$-carotene due to its reaction with radicals, which are formed due to oxidation of linoleic acid in an emulsion. The rate of $\beta$-carotene bleaching can be decreased in the presence of antioxidants. This principle is used in the determination of antioxidant activity of NNSE in comparison with BHT and ascorbic acid [32].

The FTC assay was used to determine the lipid peroxidation. The results showed that there was an increase in the absorbance of the control which reached at peak value in day 9. Thiobarbituric acid reactive substances (TBARS) are naturally equipped with biological ingredients like lipid hydroperoxides and aldehydes which increases in concentration against oxidative stress. TBARS assay values are usually mentioned as malonaldehyde equivalents. MDA formation takes place from the decomposition of polyunsaturated fatty acid due to the action of lipid peroxides. Low absorbance indicates the strong antioxidant ability. The results of the study indicate that ethanol seed extract of the plant possesses strong antioxidant activity. The TBA results were in agreement with those obtained by the FTC assay.

\section{CONCLUSION}

This study is focused on in vitro methods of antioxidant evaluation. The in vitro methods report that NNSE exhibited significant antioxidant activity. Nevertheless, the results of $\mathrm{H}_{2} \mathrm{O}_{2}$ activity, reducing power, scavenging activity, inhibition of carotene bleaching, TBA and FTC assay of NNSE revealed antioxidant activity. The broad range of antioxidant activity of NNSE indicates the potential of the seed as a source of natural antioxidants or nutraceuticals with potential application to decrease the incidence of oxidative stress with increased health benefits. Though other antioxidants are probably present in this extract, phenolic compounds might have made a significant contribution to their bioactivity. In fact, it is very difficult to attribute the antioxidant effect of NNSE to one or a few active principles, because extract always contains a mixture of different chemical compounds. The major and minor components may also make a significant contribution to the antioxidant activity. As a conclusion, this study reveals that Nelumbo nucifera is a rich source of natural antioxidant compounds. Further studies are warranted for the isolation, identification, and characterization of active principles.

\section{ACKNOWLEDGEMENT}

The first author Alok Bhardwaj is thankful to the Dr. K. P. Modi (Associate Professor) at B. K. Mody Govt. Pharmacy College, Rajkot, India, for providing general support and encouraging my work. We also thank taxonomists for identifying the plant species used in the study.

\section{CONFLICT OF INTERESTS}

\section{Declared none}

\section{REFERENCES}

1. Shies H. Biochemistry of oxidative stress. Angew Chem Int Ed 1986;25:1058-71.

2. Valko M, Leibfritz D, Moncol J, Cronin MTD, Mazur M, Telser J. Free radicals and antioxidants in normal physiological functions and human disease. Int J Biochem Cell Biol 2007;39:44-84.

3. Halliwell B, Gutteridge JMC. Free radicals in biology and medicine. 3rd Ed. Oxford (UK): Oxford University Press; 1199.

4. Keerthana G, Kalaivani MK, Sumathy A. In vitro alpha-amylase inhibitor and antioxidant activities of ethanol leaf extract of Croton bonplandianum. Asian J Pharm Clin Res 2013;6:32-26.

5. Cadens E, Davies KJA. Mitochondrial free radical generation, oxidative stress, and ageing. Free Radicals Biol Med 2000;29:222-30.

6. Shen MJ, Schopf JW, Harbottle G, Cao RJ, Ouyang S, Zhou KS, et al. Long-living lotus: germination and soil irradiation of centuries-old fruits and its cultivation, growth and phenotypic abnormalities of offspring. Am J Bot 2002;89:236-47.

7. Munish G, Singhal T. Doxorubicin-induced cardiomyopathy and its herbal solution. Int J Pharm Sci Res 2013;4:3341-6.

8. Chanda S. Importance of pharmacognostic study of medicinal plants: an overview. J Pharm Photochem 2014;2:69-73.

9. Kim UK, Jorgenson E, Coon H, Leppert M, Risch N, Drayna D. Positional cloning of the human quantitative trait locus underlying taste sensitivity to phenylthiocarbamide. Science 2003;299:1221-5.

10. Alam MN, Bristi NJ, Rafiquzzaman M. Review on in vivo and invitro methods, evaluation of antioxidant activity. Saudi Pharm J 2013;21:143-52. 
11. Jayaprakash GK, Singh RP, Sakariah KK. The antioxidant activity of grape seed extracts on peroxidation models in vitro. J Agric Food Chem 2001;55:1018-22.

12. Sreejayan, Rao MN. Nitric oxide scavenging by curcuminoids. J Pharm Pharmacol 1997;49:105-7.

13. Yildirim A, Mavi A, Kara AA. Determination of antioxidant and antimicrobial activities of Rumex Crispus $L$ extracts. J Agric Food Chem 2001;9:4083-9.

14. Dapkevicius A, Venskutonis R, Beek TA, Linssen JPH. The antioxidant activity of extracts obtained by different isolation procedures from some aromatic herbs grown in Lithuania. J Sci Food Agric 1998;77:140-6.

15. Duarte Almeida JM. Evaluation of the antioxidant activity using the $\beta$-carotene/linoleic acid system and the DPPH scavenging method. Cienc Tecnol Aliment 2006;26:446-52.

16. Osawa T, Namiki M. A novel type of antioxidant isolated from the leaf wax of Eucalyptus leaves. Agric Biol Chem 1981;45:735-9.

17. Kunitomo J, Yoshikawa Y, Tanaka S, Imori Y, Isoi Y, Masada Y, et al. Alkaloids of Nelumbo nucifera. Phytochemistry 1973; 12:699-701.

18. Vaidyaratnam PS, Variers P. Indian medicinal plants orient Longman Limited, New Delhi; 1994;1:58-9.

19. Grice HC. Safety evaluation of butylated hydroxytoluene (BHT) in the liver, lung and gastrointestinal tract. Food Chem Toxicol 1986;24:1127-30.

20. Espin JC, Soler RC, Wichers HJ, Garcia VC. Anthocyanin-based natural colourants: a new source of antiradical activity for foodstuff. J Natu Prod 2000;48:1588-92.

21. Lim SN, Cheung PCK, Ooi VEC, Ang PO. Evaluation of the antioxidative activity of extracts from brown seaweed Sargassum siliquastrum. J Agric Food Chem 2002;50:3862-6.

22. Jayaprakasha GK, Jaganmohan Rao L, Sakariah KK. Antioxidant activities of flavidin in differences in vitro model systems. Bioorg Med Chem 2004;12:5141-6.
23. Sreejayan N, Rao MNA. Nitric oxide scavenging by curcuminoids. J Pharm Pharmacol 1997;49:105-7.

24. Halliwell B. Reactive oxygen species in living systems: source, biochemistry and role in human diseases. Am J Med 1991;91:14-22.

25. Soare JR, Dinis TCP, Cunha AP, Almeida LM. Antioxidant activity of some extracts of Thymus zygis. Free Radical Res 1997;26:469-78.

26. Dorman HJD, Peltoketo A, Hiltunen R, Tikkanen MJ. Characterization of the antioxidant properties of deodorized aqueous extracts from selected Lamiaceae herbs. Food Chem 2003;83:255-62.

27. Gordon $\mathrm{MH}$. The mechanism of antioxidant action in vitro. Hudson BJF. Ed. Food antioxidants. London: Elsevier Applied Sciences; 1990. p. 1-18.

28. Kavimani S, Saminathan K, Senthil K. Antioxidant and free radical scavenging activities of Dolichandrone atrovirens using various in vitro assay models. Int J Phytopharmacol 2014;5:293-300.

29. Hagerman AE, Riedl KM, Jones GA, Sovik KN, Ritchard NT, Hartzfeld PW, et al. High molecular weight plant polyphenolics (tannins) as biological antioxidants. J Agric Food Chem 1998;46:1887-92.

30. Dröge W. Free radicals in the physiological control of cell function. Physiol Rev 2002;82:47-95.

31. Sreejayan N, Rao MNA. Nitric oxide scavenging by curcuminoids. J Pharm Pharmacol 1997;49:105-7.

32. GK Jayaprakasha, RP Singh, KK Sakariah. The antioxidant activity of grape seed (Vitis vinifera) extracts on the peroxidation in vitro models. Food Chem 2001;73:285-90.

\section{How to cite this article}

- $\quad$ Alok Bhardwaj, Ketan P Modi. Pharmacognostical screening and determination of antioxidant activity of Nelumbo nucifera gaertn ethanol seed extract by different in vitro models. Int J Pharm Pharm Sci 2017;9(3):64-70. 